УДК 336.01

ТЮРИКОВ Александр Георгиевич - доктор социологических наук, профессор; руководитель департамента социологии, истории и философии Финансового университета при Правительстве РФ (125993, Россия, г. Москва, ГСП-3, Ленинградский np-кm, 49; t-ag2013@yandex.ru)

КУНИЖЕВА Диана Анзоровна - магистрант факультета социологии и политологии Финансового университета при Правительстве РФ (125993, Россия, г. Москва, ГСП-3, Ленинградский пр-кт, 49; diana_kunizheva@mail.ru)

\title{
ФИНАНСОВО ГРАМОТНОЕ ПОВЕДЕНИЕ КАК КЛЮЧЕВОЙ КРИТЕРИЙ ПОВЫШЕНИЯ ФИНАНСОВОЙ ГРАМОТНОСТИ
}

\begin{abstract}
Аннотация. Цифровизация финансовой сферы привлекает большое внимание ученых и практиков, органов государственного управления и субъектов финансово-экономической деятельности к проблемам развития системы повышения финансовой грамотности населения в Российской Федерации, ее связи с концепциями экономического поведения. Реализация мер, повышающих финансовую грамотность населения РФ в современных условиях, происходит по нескольким направлениям. Одним из таких направлений является формирование моделей финансово грамотного поведения. В статье рассматривается вопрос эффективности реализуемых в настоящее время мер, направленных на формирование таких поведенческих моделей не только на основе объективных показателей, но и с учетом мнения участников финансовых процессов и институтов. В работе отражены результаты комплексного социологического исследования, реализованного в рамках НИР «Институционализация финансовой грамотности в РФ» в 2019 г.
\end{abstract}

Ключевые слова: финансовая грамотность, финансово грамотное поведение, стратегия повышения финансовой грамотности, поведенческие установки, критерии повышения финансовой грамотности

$\mathrm{B}$ 2017 г. Организация экономического сотрудничества и развития (ОЭСР) опубликовала результаты международного сравнительного исследования финансовой грамотности. По результатам исследования Россия заняла 25-е место в мире по уровню финансовой грамотности. Слабыми сторонами россиян в сформированной финансовой грамотности оказались: а) расчет сложного процента; б) понимание необходимости диверсификации; в) отсутствие планирования семейного бюджета; г) долгосрочное финансовое планирование.

Среди тем, формирующих финансовую грамотность, наиболее приоритетными для россиян являются: распознавание финансового мошенничества, права потребителей финансовых услуг, оценка рисков на рынке финансовых услуг, планирование доходов и расходов, планирование жизни на пенсии и др.

Причины сложившейся тенденции объясняются экспертами множеством факторов, связанных с усложнением финансового рынка в целом, распространением такого явления, как мисселинг, существованием ошибочных представлений о сути тех или иных понятий и, как следствие, выстраиванием финансовых стратегий в соответствии с этим пониманием. Одной из немаловажных причин также является низкая эффективность действующей системы повышения финансовой грамотности.

Для повышения финансовой грамотности населения и формирования грамотного финансового поведения с 2011 г. Министерство финансов РФ совместно со Всемирным банком реализует проект «Содействие повышению уровня финансовой грамотности населения и развитию финансового образова- 
ния в Российской Федерации» 1 . В 2017 г. началась реализация Стратегии повышения финансовой грамотности в Российской Федерации на 2017-2023 годы (далее - Стратегия) ${ }^{2}$. Объективные результаты проводимой государственной политики в области повышения финансовой грамотности и формирования грамотных поведенческих практик среди различных социальных групп населения необходимо подкреплять мнением участников этого процесса. Поэтому возрастает интерес научного сообщества и представителей финансовых институтов к вопросам построения эффективных и предметно направленных мер, содействующих повышению показателей.

Финансовая грамотность исследуется по различным предметным областям.

1. Изучение финансовой грамотности в контексте финансового поведения населения. Здесь следует отметить заслуги таких ученых, как Т.Ю. Богомолова, Ю.Ю. Волков, А.В. Каравай, А.А. Тихонов, П.М. Козырева, Д.Х. Ибрагимова, М.С. Щербаль.

2. Исследование финансовой грамотности и ее взаимосвязь с компетентностью. В этой области можно отметить работы О.Е. Кузиной, М.Ю. Шевякова, Н. Евсеевой, М.И. Подболотовой, Н.В. Деминой, Д.А. Шевченко, А. В. Давыденко [Кузина 2015; Подболотова, Демина 2014; Шевченко, Давыденко 2013; 2014].

3. Социологический анализ финансовой грамотности. Например, в научном исследовании Д.В. Моисеевой выделяется два подхода к определению понятия «финансовая грамотность»: 1) компетентностно ориентированный, в соответствии с которым финансовая грамотность понимается как сочетание таких компонентов, как компетенции в банковской сфере, освоение базовых сведений в финансово-экономической сфере, мотивация и 2) социокультурный, в соответствии с которым финансовая грамотность понимается как элемент финансовой культуры, включающий знания, умения, навыки, нормы, ценности, традиции [Дулина, Моисеева 2017].

4. Исследование финансовой грамотности зарубежными учеными. Например, В.Л. Антес рассматривает финансовую грамотность как способность проводить расчеты частных финансовых средств, умело использовать условия получения льготных финансовых средств, осуществлять управление частными финансами для достижения личного и семейного благополучия [Anthes 2004]. Интересным представляется подход Л. Мэнделла, который понимал под финансовой грамотностью компетентное оценивание возможностей, предлагаемых новых финансовых услуг, квалифицированное принятие решений по использованию единичных либо пакетных финансово-кредитных услуг, а также по реализации личных финансовых стратегий для получения гарантированных доходов (прибылей) [Mandell 2009]. Ученые Ф. Лусарди и П. Туфано предлагают понимать ее как способность принимать простые финансовые решения [Lusardi, Tufano 2008]. Д. Мур считает, что необходимая финансово-экономическая грамотность проявляется в компетентности по выбору финансовых услуг, а также в способности их оптимально использовать [Moore 2003]. Таким образом, в научнопрактический оборот за рубежом введены следующие дефиниции феномена финансовой грамотности: а) понимание ее как специфической формы знаний; б) сформированное умение или уверенный навык применять имеющиеся знания; в) глубоко освоенная совокупность сведений, представляющих финансо-

\footnotetext{
1 Проект «Содействие повышению уровня финансовой грамотности населения и развитию финансового образования в Российской Федерациџ». Т. 1. 2011-2015: справочно-информационное издание. Минфин России. 2016. С. 75-76.

2 Стратегия повышения финансовой грамотности в Российской Федерации на 2017-2023 годы (утв. распоряжением Правительства РФ от 25.09.2017 № 2039-p). Доступ: http://publication. pravo.gov.ru/Document/View/0001201709290002 (проверено 22.01.2020).
} 
вое знание; г) эффективное, финансово грамотное поведение; д) приобретенный финансовый опыт.

Приведенный выше анализ научной литературы позволяет сделать вывод, что имеется множество определений финансовой грамотности. В то же время общим в них является способность человека управлять финансами.

Согласно авторскому определению, понятие «финансовая грамотность» это показатель осведомленности, знаний и умений, в соответствии с которыми принимаются осознанные финансовые решения. Критерием таких решений является финансово грамотное поведение в контексте формируемой финансовой культуры населения.

Исследования вопросов финансовой грамотности набирают актуальность в российском обществе. Проведенный контент-анализ баз данных крупнейших российских информационно-аналитических порталов в области науки и электронных библиотек (Российская государственная библиотека, Библиотека диссертаций и авторефератов DsLib.net, Научная электронная библиотека eLIBRARY.RU) выявил возрастание интереса в академической среде к темам финансовой грамотности и финансового поведения (см. рис. 1).

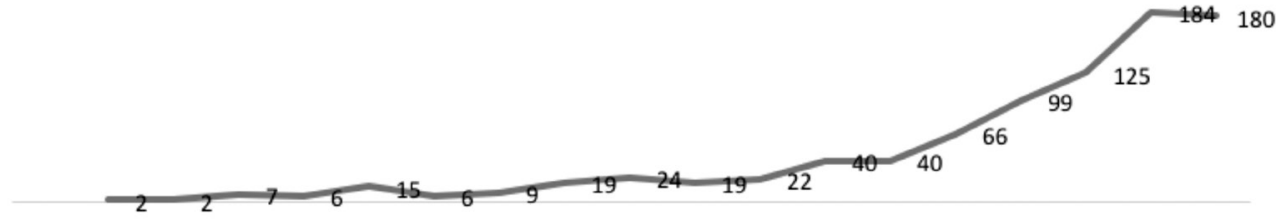

2000200120022003200420052006200720082009201020112012201320142015201620172018

Рисунок 1. Общее упоминание темы финансовой грамотности в названиях российских научных трудов (диссертации, монографии, статьи) в период с 2000 по 2018 г.

Современный этап развития финансового рынка требует постоянного повышения финансовой грамотности россиян. Формирование у граждан осведомленности, знаний и умений в финансовых вопросах необходимо не только для общей грамотности населения, но и для создания финансово грамотных поведенческих установок.

В настоящее время состояние финансовой грамотности населения России остается пока на низком уровне, что обусловлено следующими проблемами:

1) не в полной мере выстроены коммуникационные механизмы взаимодействия между государством и обществом, связанные с результативностью финансовой грамотности и ее взаимосвязью с различными компонентами экономической культуры населения РФ;

2) в принятой Стратегии отмечается фрагментарный характер преподавания основ финансовой грамотности в образовательных организациях, а также недостаток квалифицированных преподавателей и их компетенций по основам финансовой грамотности в части защиты прав потребителей финансовых услуг;

3) в гражданском обществе сформировалась убежденность в ответственности государства за принимаемые гражданами ошибочные финансовые решения, а также отсутствует доверие к финансовой системе со стороны населения;

4) граждане имеют низкий уровень информированности о правовых меха- 
низмах защиты прав потребителей финансовых услуг на федеральном уровне и уровне субъектов РФ;

5) граждане не в полной мере осознают важность и значимость финансового планирования своего бюджета. Например, по исследованиям Национального агентства финансовых исследований $\left(\right.$ НАФИ) ${ }^{1}$, не более $10 \%$ российских семей планируют свои расходы на срок более месяца, а в Стратегии отмечается, что только в каждом 4-м домохозяйстве ведется письменный учет доходов и расходов, причем $22 \%$ населения отметили, что выплаты по кредиту занимают более $30 \%$ доходов, а $68 \%$ из них отметили, что отдают более $50 \%$ своих доходов;

6) абсолютное большинство граждан не знают, куда они могут обратиться за защитой своих прав в случае недобросовестного оказания им финансовых услуг. Многие считают, что этими вопросами занимается Сбербанк России. К сожалению, редко упоминают Центробанк и Роспотребнадзор России. Кроме того, более $60 \%$ из них не станут этого делать, будучи уверенными, что у них нет шансов выиграть в суде спор с банком.

Методика. На 1-м этапе научно-исследовательской работы была разработана концептуальная модель современного состояния финансовой грамотности и финансового поведения населения России. На 2-м этапе проведен экспертный опрос (выборочная совокупность $N=150$ ), в результате которого были выявлены факторы, формирующие финансово грамотное и неграмотное поведение населения; модели финансово грамотного поведения (см. табл. 1). На 3-м этапе был реализован массовый опрос молодежи: студенты высших учебных заведений (выборочная совокупность $N=4500$ ) и школьники (выборочная совокупность $N=850)$.

Результаты. Экспертный опрос проведен в 2019 г. среди представителей финансовых, государственных и образовательных структур из 30 регионов РФ. Эксперты оценивали эффективность мер, повышающих финансовую грамотность населения, по следующим реализуемым в настоящее время в РФ направлениям: финансовое просвещение и информирование, обучение финансовой грамотности, формирование моделей финансово грамотного поведения, обеспечение доступности финансовых услуг, защита прав потребителей финансовых услуг. В целом эксперты низко оценили эффективность реализуемых мер, однако наиболее критичным оказалось направление, ориентированное на формирование моделей финансово грамотного поведения. $71 \%$ экспертов отметили низкую эффективность реализуемых мер по данному направлению.

Опрос экспертов и массовый опрос молодежи выявил модели финансово грамотного поведения в современных условиях.

Результаты анализа опросов демонстрируют разницу в мнениях: согласно экспертному мнению, финансово грамотным являются модели поведения, связанные с реальными действиями и поведенческими практиками, в то время как молодежь указывает теоретизированные направления и области знаний, формирующие общую финансовую грамотность населения.

Далее были выявлены модели поведения, не являющиеся приоритетными в современных социально-экономических условиях. По мнению экспертов, такими являются: а) обращение за потребительскими кредитами и автокредитами; б) использование кредитных карт; в) заключение договора пожизненной

\footnotetext{
1 Россия занимает 25-е место по уровню финансовой грамотности в мире. - НАФИ. 02.11.2016. Доступ: https://nafi.ru/analytics/rossiya-zanimaet-25-e-mesto-po-urovnyu-finansovoy-gramotnostiv-mire/ (проверено 22.01.2020); Рейтинг финансовой грамотности россиян - 2018. - НАФИ. Доступ: https://nafi.ru/projects/finansy/reyting-finansovoy-gramotnosti-regionov-rossii-2018/ (проверено 22.01.2020).
} 
Таблица 1

\section{Модели финансово грамотного поведения}

\begin{tabular}{|l|l|}
\hline \multicolumn{1}{|c|}{ По мнению экспертов } & \multicolumn{1}{|c|}{ По мнению молодежи } \\
\hline $\begin{array}{l}\text { Инвестировать свои средства только в } \\
\text { то, что можно контролировать самому - } \\
\text { недвижимость, собственный бизнес и т.п. }\end{array}$ & $\begin{array}{l}\text { Уметь эффективно управлять личными } \\
\text { финансами }\end{array}$ \\
\hline $\begin{array}{l}\text { Уметь искать финансово значимую } \\
\text { информацию }\end{array}$ & $\begin{array}{l}\text { Знать возможности финансовых } \\
\text { инструментов для достижения своих } \\
\text { целей }\end{array}$ \\
\hline $\begin{array}{l}\text { Распознавать признаки финансового } \\
\text { мошенничества }\end{array}$ & $\begin{array}{l}\text { Уметь разбираться в особенностях } \\
\text { различных финансовых продуктов и } \\
\text { услуг }\end{array}$ \\
\hline $\begin{array}{l}\text { Планировать свои финансы (доходы и } \\
\text { расходы) }\end{array}$ & \\
\hline $\begin{array}{l}\text { Уметь анализировать ситуацию на } \\
\text { финансовом рынке с целью выявления } \\
\text { рисков для управления своими финансами }\end{array}$ & \\
\hline
\end{tabular}

ренты ради получения добавки к пенсии; г) размещение всех своих сбережений на банковских депозитах.

Молодежь, в отличие от экспертов, считает наиболее адекватными финансовой грамотности следующие поведенческие модели: наличие таких инновационных финансовых инструментов, как электронный кошелек и пользование банковской картой.

По результатам опроса был определен набор факторов, наиболее положительно влияющих на финансовое поведение россиян, среди которых по степени значимости: достойный уровень дохода, уверенность в завтрашнем дне; доступность информации; образование граждан и финансовая стабильность.

Негативное влияние на финансовое поведение россиян оказывают следующие факторы:

- низкий уровень доходов, на это указали 31,6\% экспертов;

- нестабильность экономики, финансовой системы - 27,2\%;

- отсутствие защиты прав потребителей и недоверие к государственным и финансовым институтам, в сумме это отметили 23,5\% экспертов.

Оценка целевых групп населения по уровню их финансовой грамотности позволила сформулировать следующие выводы: а) наиболее финансово грамотными являются работники финансовой сферы, студенты, обучающиеся по профильным специальностям, предприниматели; б) наименее финансово грамотными являются пенсионеры, лица с низким доходом, жители сел.

Результаты опроса экспертов и массового опроса молодежи определили высокую необходимость формирования моделей финансово грамотного поведения как критерия повышения финансовой грамотности населения. Помимо этого, основными направлениями повышения финансовой грамотности, по мнению экспертного сообщества, являются финансовое просвещение и информирование; обучение финансовой грамотности; обеспечение доступности финансовых услуг; защита прав потребителей финансовых услуг.

Финансовая грамотность населения заключается не в том, чтобы каждый знал, как рассчитываются проценты по кредитным картам и налоговым взносам. Главное, чтобы люди понимали, как использовать свои ресурсы: куда вкладывать деньги, чтобы не потерять их, а прирастить, чтобы деньги работали в первую очередь на тех, кто их зарабатывает честным путем, чтобы деньги не 
попали в пирамиды, приносили доход собственнику и работали на экономику. Применение грамотных финансовых поведенческих стратегий является критерием сформированности у населения высокой финансовой грамотности.

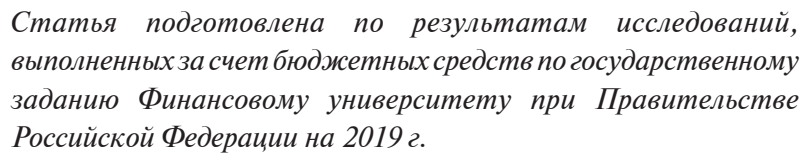
выполненныхза счет бюджетныхсредств по государственному заданию Финансовому университету при Правительстве Российской Федерации на 2019 г.

\section{Список литературы}

Дулина Н.В., Моисеева Д.В. 2017. Финансовая грамотность населения как результат процесса финансового образования (на примере Волгоградской области). - Вестник Сургутского государственного педагогического университета. № 5(50). С. 163-168.

Кузина О.Е. 2015. Финансовая грамотность и финансовая компетентность: определение, методики измерения и результаты применения в России. Вопросы экономики. № 8. С. 129-148.

Подболотова М.И., Демина Н.В. 2014. Финансовая грамотность как компетентность выпускника общеобразовательной школы: структура и содержание. - Академический вестник. № 1(14). С. 10-16.

Шевченко Д.А., Давыденко А.В. 2013. Финансовая грамотность населения как фактор сберегательного поведения домашних хозяйств. - Terra Economicus. T. 11. № 4-2. С. 139-144.

Шевченко Д.А., Давыденко А.В. 2014. О содержании и взаимосвязи понятий «финансовая грамотность» и «финансовая культура». - Финансовые аспекты модернизации экономики России. Ростов н/Д: Фонд инноваций и экономических технологий «Содействие - XXI век». С. 100-105.

Anthes W. L. 2004. Financial Illiteracy in America: A Perfect Storm, a Perfect Opportunity. - Journal of Financial Service Professionals. Vol. 58. No. 6. P. 49-56.

Lusardi A., Tufano P. 2008. Debt Literacy, Financial Experience, and Overindebtedness. NBER Working Paper No. 14808. 46 p.

Mandell L. 2009. The Impact of Financial Literacy Education on Subsequent Financial Behavior. - Journal of Financial Counseling and Planning. Vol. 20. Is. 1. P. 15-24.

Moore D. 2003. Survey of Financial Literacy in Washington State: Knowledge, Behavior, Attitudes, and Experiences. - Social and Economic Sciences Research Center Technical Report. 03-39. Pullman, WA: Washington State University.

TYURIKOV Aleksandr Georgievich, Dr.Sci. (Soc.), Professor, Head of the Department of Sociology, History and Philosophy, Financial University under the Government of the Russian Federation (49 Leningradsky Ave, GSP-3, Moscow, Russia, 125993; t-ag2013@yandex.ru)

KUNIZHEVA Diana Anzorovna, Master Student at the Faculty of Sociology and Political Science, Financial University under the Government of the Russian Federation (49 Leningradsky Ave, GSP-3, Moscow, Russia, 125993; diana_ kunizheva@mail.ru)

\section{FINANCIALLY COMPETENT BEHAVIOR AS A KEY CRITERION FOR IMPROVING FINANCIAL LITERACY}

Abstract. The digitalization of the financial sector has attracted great attention of scientists and practitioners, public authorities and subjects of financial and economic activity to the problems of developing a system for improving the financial 
literacy of the population in the Russian Federation, its connection with concepts of economic behavior. Implementation of measures that increase the financial literacy of the population in modern conditions in the Russian Federation takes place in several areas. One of these areas is the formation of financially competent behavior models. The article addresses the issue of the effectiveness of currently implemented measures aimed at the formation of such behavioral models not only based on objective indicators, but also taking into account the views of participants in financial processes and institutions. The work reflects the results of a comprehensive case study, which includes an expert survey of 150 representatives of financial, state and educational institutions from 30 regions of the Russian Federation and a mass survey of Russian youth, including 4,500 students and 850 schoolchildren.

Keywords: financial literacy, financially competent behavior, strategy for improving financial literacy, behavioral attitudes, criteria for increasing financial literacy

ВАГАПОВА Фирдаус Габдуллазяновна - кандидат филологических наук, доцент; старший научный сотрудник Ресурсного центра по развитию исламского и исламоведческого образования Института международных отношений Казанского (Приволжсккого) федерального университета (420008, Россия, Республика Татарстан, г. Казань, ул. Пушкина, 1/55, корп. 312)

ВАГАПОВ Ренат Наильевич - кандидат политических наук; советник отдела профилактики экстремизма на религиозной почве Управления мониторинга в сфере межнациональных и межкконфессиональных отношений ФАДН России

УСТИНКИН Сергей Васильевич - доктор исторических наук, профессор; декан факультета международных отношений, экономики и управления, профессор кафедры международных отношений и политологии Нижегородского государственного лингвистического университета им. Н.А. Добролюбова (603155, Россия, г. Нижний Новгород, ул. Минина, 31а); директор Приволжского филиала Федерального научно-исследовательского социологического иентра РАН (603000, Россия, г. Нижний Новгород, пер. Холодный, 4; sv.ustinkin@gmail.com)

\section{НЕКОММЕРЧЕСКАЯ ОРГАНИЗАЦИЯ (НКО) В СОЦИАЛЬНО-ПОЛИТИЧЕСКИХ ПРОЦЕССАХ СОВРЕМЕННОЙ РОССИИ: ТЕОРЕТИЧЕСКИЙ АСПЕКТ}

Аннотация. Современное состояние гражданского общества России представляет особый интерес и актуальность при рассмотрении возможности гражданского участия общественных объединений в политических процессах современной России. Для общественности становятся приоритетным объектом внимания вопросы выстраивания отношений органов власти и структур гражданского общества в различных областях политики, участия некоммерческих организаций в разработке и претворении в жизнь политического курса государства. Необходимо рассматривать НКО как полноценных акторов социальной политики, которые выполняют функции в сфере социальной заботы и защиты, аналогичные государственным.

Ключевые слова: неправительственные некоммерческие организации, социально-политический процесс, гражданское общество России

$\mathrm{H}$ а рубеже тысячелетий процесс активизации гражданской деятельности дал толчок возникновению и развитию гражданского общества.

Гражданское общество часто рассматривает «третий сектор» как действующий независимо от двух других секторов общества - государства и рынка, но в то же время играющий роль посредника между ними. Этот третий сектор должен состоять из организаций, которые имеют формальную структуру и незави- 